\title{
PENGATUR LAMPU LALU LINTAS SISTEM DIGITAL BERBASISKAN MIKROCONTROLER
}

\author{
Oleh
}

Suryadi

Staf Pengajar Teknik Elektro Politeknik Negeri Padang

\begin{abstract}
traffic light still uses analog system with discrete component. This technology has many disadvantages for example difficulty in maintenance and repair, display only to lamp without counter and no control for delay in normal hours or rush hours. These can be cause traffic jam and accident.

To solve this problem, traffic light system is completed by digital system and buzzer using microcontroller AT89C51.

The observation result to prototype at laboratory in Polytechnic State of Padang show this system can be implemented to real condition.
\end{abstract}

Keyword: traffic light, buzzer, prototype

\section{PENDAHULUAN}

Traffic light yang diterapkan pada saat sekarang ini masih menggunakan sistem konvensional dengan menggunakan komponen diskrit seperti transistor resistor relay,timer dan lainlainnya yang hanya menampilkan lampu lalu lintas tanpa adanya pencacah dan pengaturan perbedaan waktu untuk keadaan kendaraan padat dan normal, ditambah lagi apabila terjadi kerusakan pada salah satu komponen pada modul lampu lalu lintas tersebut akan menambah permasalahan menjadi rumit karena perbaikan dan pemeliharaan dari sistem konvesional tersebut sangat sulit sehingga kejadian ini dapat menyebabkan kemacetan dan bahkan kecelakaan. terutama sekali di persimpangan yang padat kendaraan.
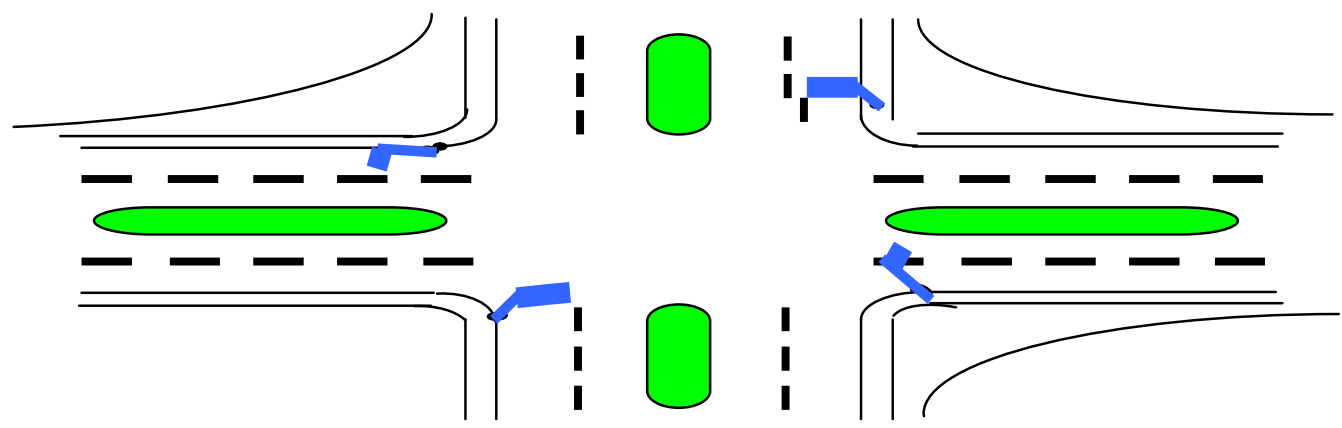

Gambar.1 Skema persimpangan jalan. 
Traffic light ini tercipta karena semakin tingginya tingkat mobilitas penduduk pada suatu daerah. Banyaknya pengguna jalan dari berbabagai jenis kendaraan yang membutuhkan keselamatan saat melewati persimpangan jalan, membuat orang terus berupaya untuk merancang suatu sistem traffic light yang dapat meringankan beban polisi dalam mengatur kelancaran arus lalu lintas dan menjaga keselamatan bagi pengguna jalan.

Karena pentingnya keselamatan dan kelancaran lalu lintas bagi pengguna jalan terutama di persimpangan, maka penulis mencoba untuk membuat traffic light dengan sistem digital berbasiskan Mikrokontroler untuk meningkatkan tingkat keselamatan dan kelancaran arus lalu lintas.

\section{METODE PENYELESAIAN}

Sejumlah teknik telah dicoba untuk mengatur masalah lalu lintas di persimpangan jalan (perempatan) dimulai dari menggunakan manusia seperti Polisi lalu lintas dari cara ini banyak kelamahan yang terjadi salah satunya adalah tidak bisa bekerja secara terus menerus (selama 24 jam) dan selalu mempunyai kecendrungan dalam bertindak.

Suatu metode penggunaan lampu diatur secara manual dimana warna sinar lampu untuk menandakan boleh jalan, bersiap-siap atau berhenti contohnya adalah sinar lampu warna hijau ,kuning dan merah yang mana waktu hidupnya

Blok Diagram Traffic Light lampu diatur tetap secara bergilir oleh operator cara ini juga banyak ditemukan kelemahannya diantaranya adalah pengaturan waktu yang kaku serta membutuhkan peralatan yang besar dan sulit untuk melakukan perawatan dan perbaikan.

Pada umumnya lampu lalu lintas untuk persimpangan jalan yang ada sekarang ini di Sumatera Barat adalah sistem analog yang pengaturannya tanpa operator (otomatis) dengan referensi waktu yang dibuat menggunakan komponen diskrit yang dirangkai diatas papan rangkaian kemudian digabung dengan komponen tambahan seperti Timer, relay dan lainlain sistem analog otomatis ini juga banyak kelemahannya membutuhkan tempat yang besar dan biaya pembelian, perawatan perbaikannya sulit.

Makalah ini mepresentasikan pembuatan alat yang praktis dan andal yang dikembangkan untuk menyelesaikan problem pengaturan lalu lintas dipersimpangan jalan mengunakan komponen terpadu Microcontroler dengan sistem digital yang ekonomis dan handal.

\section{FORMULASI PERMASALAHAN}

Dalam membuat suatu sistem (alat) perlunya perancangan yang teliti tentang apa yang akan dibuat perancangan dan sistimatika yang baik akan memberikan kemudahan dalam proses pembuatan alat. 


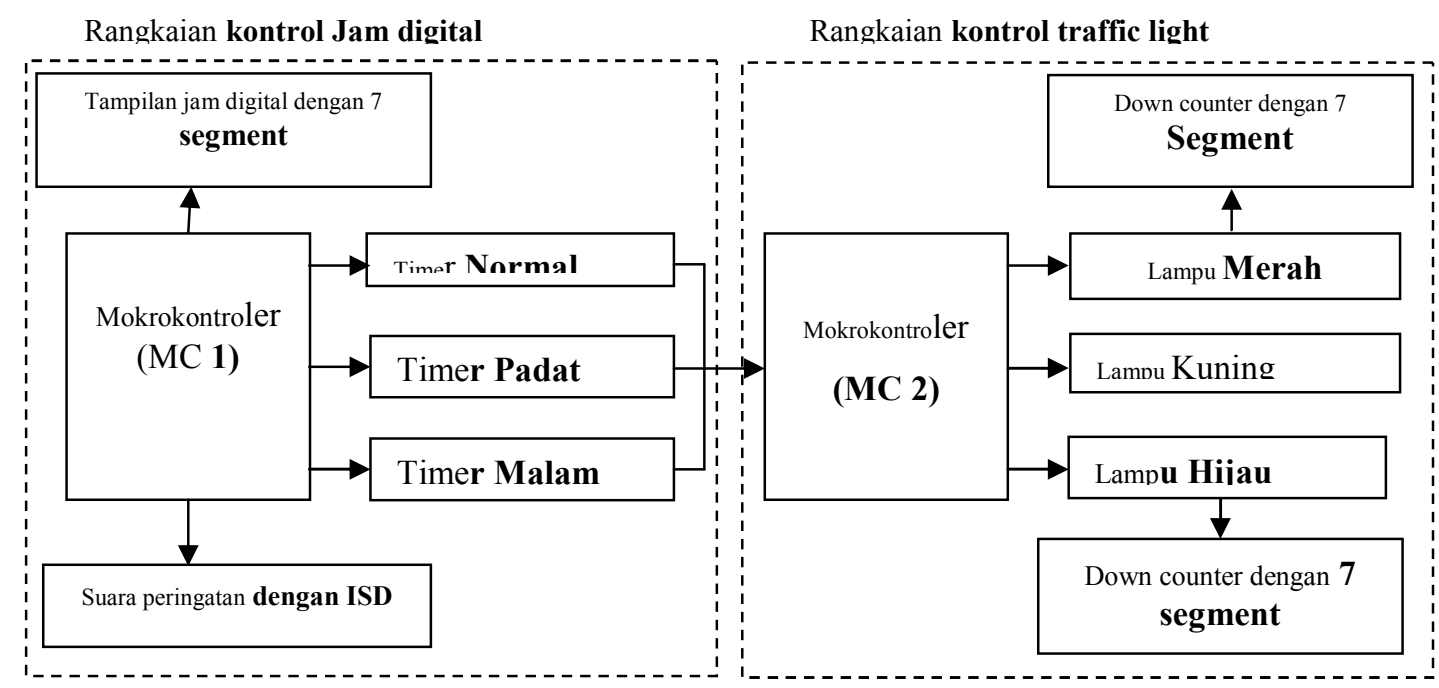

Gambar 2. Blok diagram traffic light

Pada Blok diagram diatas dapat diterangkan bahwa rangkaian kontrol MC1 merupakan pengontrol utama yang memiliki output berupa tampilan jam digital, dan tampilan pada jam digital ini sebagai data pembanding untuk kontrol Traffic Light serta input bagi ISD (Information Storage Device). MC pada rangkaian jam digital akan memberikan inisialisasi kepada MC rangkaian traffic light atas tiga macam keadaan yaitu normal, padat, dan malam. Selanjutnya dikirimkan pada rangkaian kontrol MC2 yang merupakan pengontrol utama dari rangkaian traffic light yang memiliki output berupa lampu traffic light serta tampilan seven segmen sebagai peraga dari pencacah.

\section{Rangkaian Kontrol Traffic Light}

Untuk pengontrolan traffic light ini digunakan Mikrokontroler AT89C51 yang telah deprogram terlebih dahulu. Rangkaian ini akan di desain pada sebuah

\section{Rangkaian Serial Input Paralel Output}

Rangkaian lampu traffic light yang digunakan, juga dilengkapi oleh IC 74LS164 yang dimanfaatkan sebagai shift register, yang memiliki output
PCB dengan memakai konektor sebagai penghubung per bloknya. Rangkaian ini akan diusahakan serapi dan seefisien mungkin sehingga tidak terlalu memakan tempat.

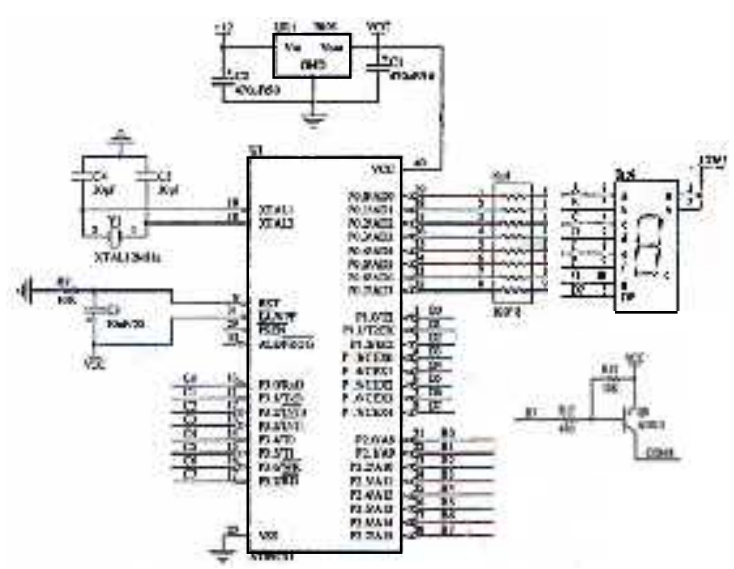

Gabar 3. Kontrol Traffic Light dan Jam Digital

paralel dengan sistem menggeser satusatu atau dikenal dengan serial input dan paralel output. 


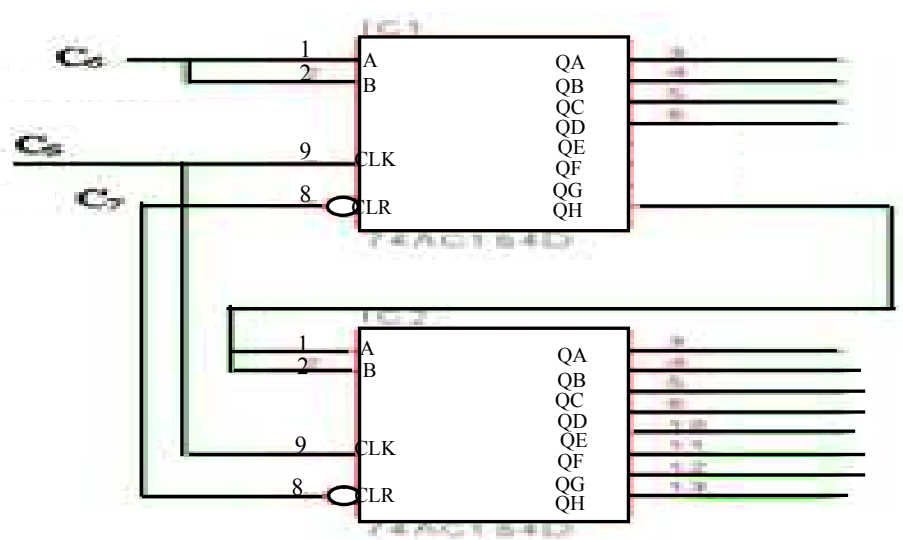

Gambar 4. Rangkaian serial input paralel output

\section{Rangkaian Suara Peringatan (ISD}

\section{Kit)}

Pada rangkaian suara ini digunakan ISD

(Information Storage Device) yang merupakan salah satu dari komponen

elektronika yang memiliki sebuah

Single-Chip ( CMOS ). Dalam perkembangannya Chip ini dapat digunakan untuk record / play back, dengan durasi waktu yang cukup bervariasi. Seri dari ISD 2500 ini sangat ditentukan oleh durasi waktu yang digunakan pada suatu sistem.

1502530

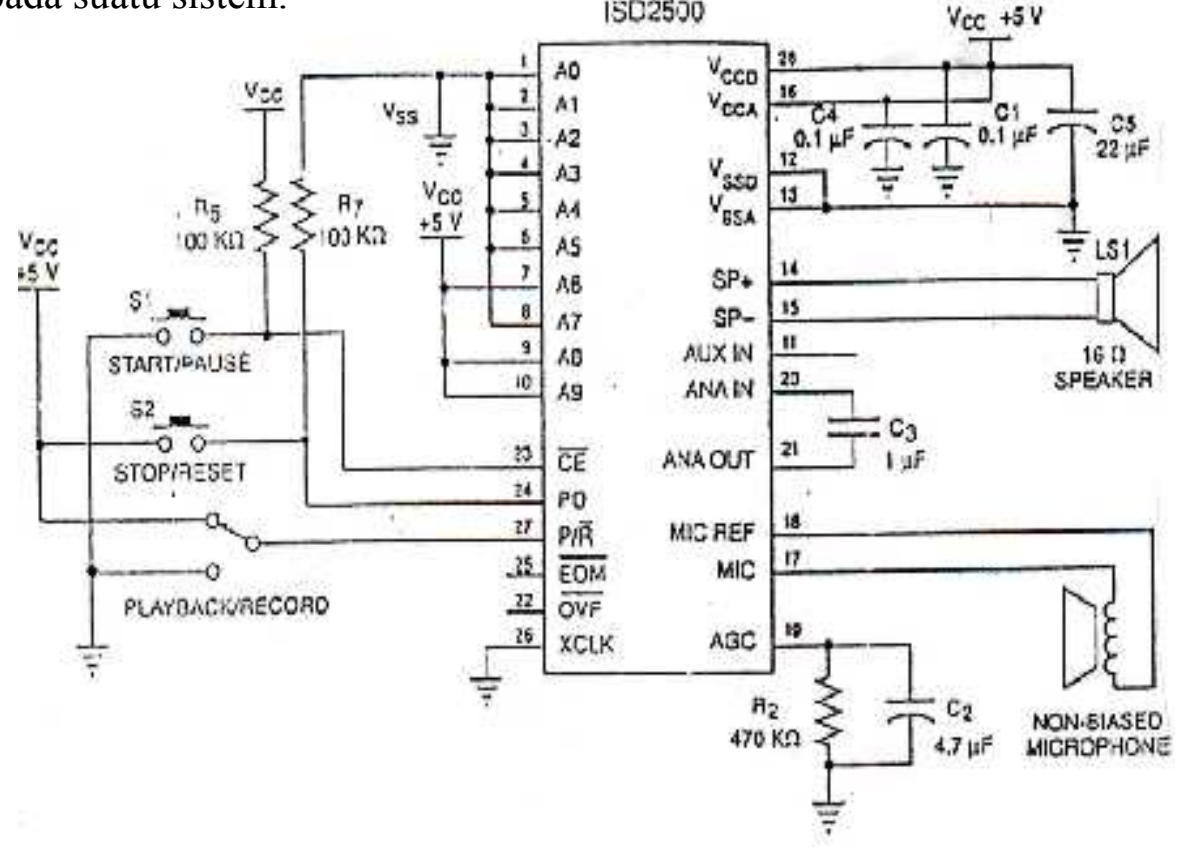

Gambar 5. Rangkaian suara peringatan 


\section{Tahap Software}

Adapun algoritma program pengendali traffic light ditunjukan dalam flowchart dibawah ini.

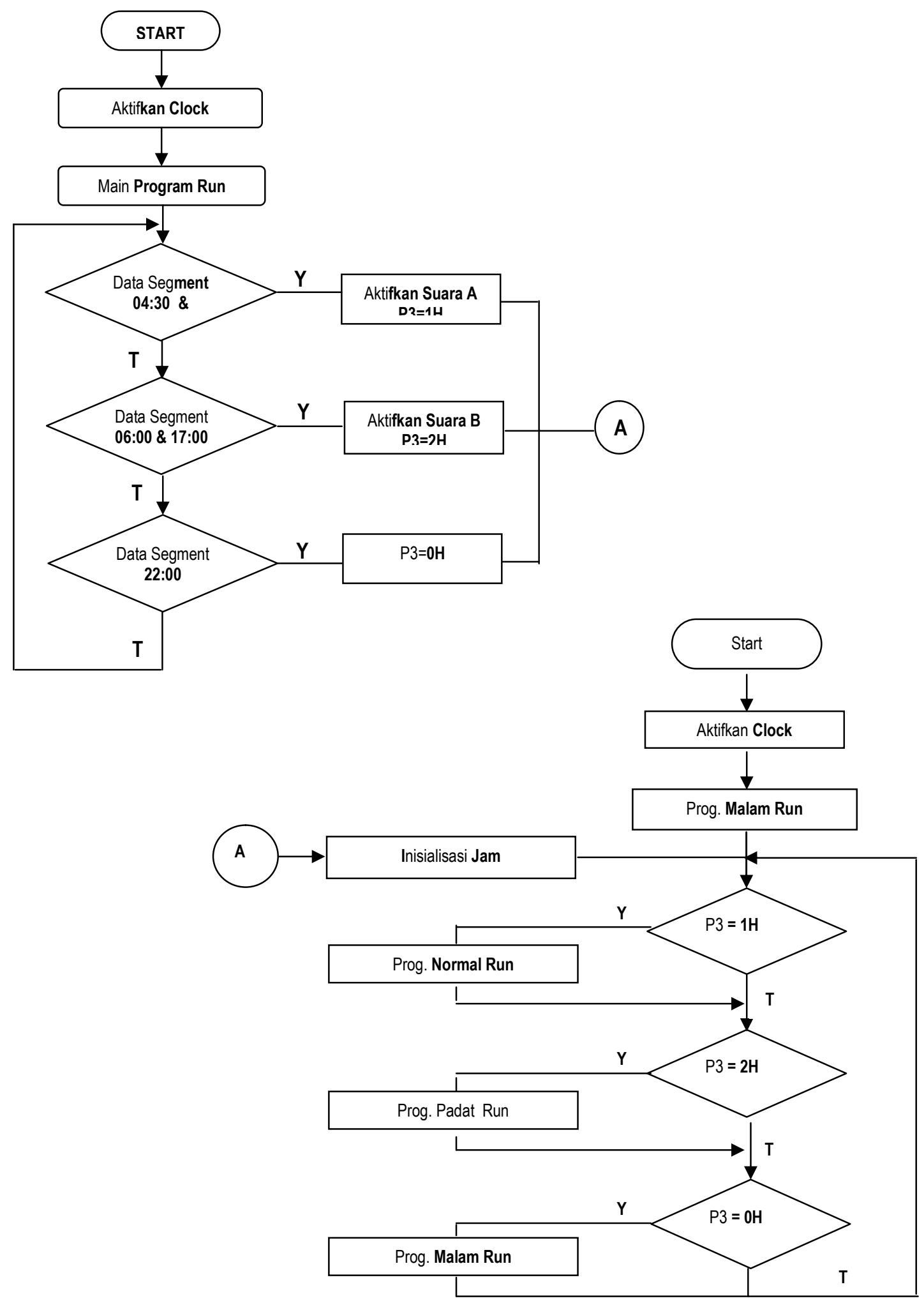

Gambar 6. Algoritma program unit pengendali traffic light 


\section{HASIL}

Pada Lampu lalu lintas (traffic light) dengan sistem waktu digital dan suara peringatan ini dibuat dalam bentuk Miniatur digunakan dua buah Mikrokontroler AT89C51 yaitu satu buah untuk pengontrolan jam digital beserta ISD kit dan satu lagi untuk pengontrolan traffic light. Jam digital digunakan sebagai alat peraga untuk menunjukkan waktu dan sebagai pengatur timer traffic light itu sendiri. Timer ini dapat diatur sesuai dengan waktu yang diinginkan, pada perancangan traffic light ini digunakan 3 aturan waktu yaitu:
1. Kondisi padat berlaku dari pukul $06.00 \mathrm{~s} / \mathrm{d} \quad 08.00$, dan pukul $17.00 \mathrm{~s} / \mathrm{d}$ 19.30 .

2. Kondisi malam berlaku dari pukul $22.00 \mathrm{~s} / \mathrm{d} 04.30$.

3. Selain dari kondisi diatas adalah kondisi normal.

Dengan adanya pengaturan timer ini, maka lampu traffic light akan menyala menurut keadaan waktunya, sehingga nyala lampu akan berbeda pada setiap kondisi yang akan mengurangi resiko kemacetan dan kecelakaan pada persimpangan. Untuk kondisi lampu untuk tiap simpangnya dapat dilihat pada Table dibawah ini.

\begin{tabular}{|l|l|l|l|l|}
\hline Keadaan & Simp. I & Simp. II & Simp.III & Simp. IV \\
\hline Normal & Hijau & Merah & Merah & Merah \\
& 10 & 12 & 24 & 36 \\
\hline Padat & Hijau & Merah & Merah & Merah \\
& 20 & 22 & 44 & 66 \\
\hline Malam & Kuning & Kuning & Kuning & Kuning \\
& On /off & On / off & On / off & On / off \\
\hline
\end{tabular}

Tabel 1. Keadaan lampu di tiap-tiap simpang

Untuk tampilan hitungan waktunya digunakan seven segment sebagai peraga. Pada seven segment ini akan ditampilkan lamanya waktu suatu lampu hidup baik itu lampu merah maupun lampu hijau. Untuk hitungannya menggunakan hitungan mundur (down counter). Tampilan waktu pada seven segment ini akan berjalan secara otomatis menurut warna lampu dan situasi. Pada saat lampu merah sedang hidup, maka secara otomatis akan terdengar suara peringatan yang mengingatkan pengendara untuk selalu berhati-hati dan mematuhi peraturan lalu lintas agar terhindar dari kecelakaan.

\section{KESIMPULAN}

Berdasarkan Percobaan yang dilakukan dalam bentuk miniatur traffic light sistem digital dengan suara peringatan menggunakan mikrokontroler di laboratorium Politeknik Universitas andalas, maka dapat disimpulkan sebagai berikut:

1. Besar tegangan picu untuk mikrokontroler sebesar $4.5 \mathrm{Vdc}-5$ Vdc, sedangkan besar tegangan output untuk aktif tinggi dari mikrokontroler adalah $4 \mathrm{~V}-5 \mathrm{~V}$ dan untuk aktif rendah berkisar $0 \mathrm{~V}-2 \mathrm{~V}$.

2. Traffic light ini dapat membantu proses kelancaran arus lalu lintas pâtla persimpangan, baik pada 
keadaan ramai, normal maupun malam hari.

3. Dengan adanya tampilan pencacah untuk lama hidupnya lampu traffic light, maka pengendara dapat mengetahui kapan suatu lampu itu akan hidup atau mati, sehingga pengendara tidak lengah yang dapat menyebabkan kemacetan dan kecelakaan.

4. Suara peringatan tertib lalu lintas yang disampaikan melalui ISD, bertujuan untuk mengingatkan kembali pengendara agar selalu mematuhi ketertiban lalu lintas.

\section{Keterbatasan}

Miniatur traffic light dengan sistem digital dan suara peringatan menggunakan mikrokontroler ini hanya khusus untuk 4 simpang dan 4 arah. Pengaturan lama hidupnya lampu telah diprogram terlebih dahulu pada mikrokontroler traffic light, sehingga untuk merubah lama hidupnya lampu harus diprogram ulang.

Karena rangkaian pada alat ini hanya untuk miniatur, maka untuk penyampaian suara peringatan digunakan speaker kecil tanpa alat pendukung lainnya, sehingga suara yang dihasilkan kurang bersih. Maka untuk keadaan yang sebenarnya harus ditambahkan rangkaian pendukung yang berkualitas.

\section{SARAN}

Pada pembuatan miniatur ini ada beberapa saran yang dapat dikemukakan untuk kesempurnaan dan pengembangan masa mendatang antara lain:

1. Agar alat ini lebih efisien lagi maka sebaiknya untuk pengaturan lama waktu hidup lampu yang akan digunakan bisa diatur hanya dengan menggunakan saklar tanpa harus memprogram ulang. Untuk perubahan itu cukup dengan menambahkan program untuk inputan saklar.

2. Karena rangkaian pada alat ini hanya untuk miniatur, maka untuk rangkaian ISD harus ditambahkan dengan alat perekam dan pengeras yang berkualitas.

3. Pada keadaan yang sebenarnya, untuk rangkaian lampu harus ditambahkan rangkaian relay ( Lampiran 2 ) dan menukar lampu traffic light dengan lampu neon atau susunan LED yang telah dirancang. Untuk pemakaian relay sebaiknya digunakan relay yang bermutu tinggi seperti HKE yang memiliki ampere besar.

\section{DAFTAR PUSTAKA}

Ibrahim, K.F., 2001, Teknik Digital Ed. I Yogyakarta : Andi

Malvino., 1994, Prinsip-Prinsip Elektronika Ed. III, Jakarta : Erlangga

Putra, Agfianto Eko., 2004, Belajar

Mikrokontroler AT89C51/52/53

Teori dan Aplikasi Ed. II, Yogyakarta :Gava Media

Setiawan, Rachmad., 2006, Mikrokontroler MCS-51 Ed.I, Yogyakarta : Graha : Ilmu

http://www.fairchildsemi.com/ MC7805 http://www.innovativeelectronic.com http://www.preliminarydatasheet.com ISD 
ISSN: 2085-6989 